\title{
USES OF NATIONAL INCOME ESTIMATES IN UNDER-DEVELOPED AREAS
}

\author{
by Daniel Creamer
}

\section{CHARACTERISTICS OF UNDER-DEVELOPED AREAS}

IN discussing the uses of national income estimates in underdeveloped areas, I shall follow accepted tradition by indicating briefly what I mean by 'national income', 'estimates' and 'under-developed areas'. Let us consider first 'under-developed areas'.

There is a greater area of agreement in the identification of under-developed economies, which, incidentally, can be made without the existence of, or reference to, national income estimates, than in the identification of the economic and social characteristics that define the status of being under-developed. This agreement stems perhaps from the vastness of the regions that must be categorized as under-developed on the basis of Western standards. In fact, all the lands of the world, with the exception of northern, central and western Europe including Great Britain, the United States, Argentina, Uruguay (perhaps), Japan and the self-governing dominions of the British, are characterized by such low per capita levels of reproducible wealth and hence of goods and services that they must be classified as under-developed, or less euphemistically, backward regions. Even this listing exaggerates the extent of the developed areas since it assumes that all parts of each of the nations mentioned have achieved a highly developed economy - Mississippi as well as Pennsylvania.

Obviously not all the backward areas can be said to have a market economy in which the majority of transactions are effected by a medium of exchange. I believe that for such primitive economies, based on self-sufficient 'households' or direct barter of goods and services, national income estimates have severely limited applicability, and if estimates are contrived for such inarticulated economies, they can have but little economic meaning.

Even limiting the subject to backward areas with market economies, the characteristic features of under-development are 
not easily determinable because of the heterogeneity of the areas concerned, both economically and socially. This heterogeneity is an evident fact which is frequently overlooked.

The following statements recur as descriptive generalizations:

(1) These areas are producers of raw materials, products of agriculture or of the mines, and each area is dependent upon the production of a single commodity.

(2) This production is predominantly under the control of absentee owners who operate through large corporate enterprises. Where the single commodity is a product of monoculture, huge corporate plantations owned by outsiders coexist with small peasant plots.

(3) Because of the dependence upon a single commodity, foreign trade is a relatively high percentage of the total trade of the area.

(4) Their political status is that of colonialism which entails, among other things, either economic concessions to the metropolitan interests or subsidies from the metropolitan government and the coexistence of two widely differing cultural communities with virtually no contact between them.

(5) High ratio of population to arable land.

(6) Low literacy rate.

(7) Low reproducible capital per head of population.

It is my contention that only the last characteristic is common to all under-developed areas, and although it can be found in conjunction with a large variety of combinations of other economic and social characteristics, it is this low ratio of capital to population that is the essential economic characteristic of a backward area. When this condition is not present, the area, by definition, is not under-developed.

The mere mention of the extreme variation in geographic coverage suggests also the absence of homogeneity among under-developed regions: these regions vary from a continent (Asia) to a few mountain peaks that emerge above the ocean's surface (the U.S. Virgin Isles).

In dealing with under-developed countries, then, we are concerned with highly heterogeneous units of population and land 
areas which share only one common characteristic-low amounts of reproducible capital per head of population. ${ }^{1}$

\section{NATIONAL INCOME ESTIMATES}

We can indicate more briefly what meaning we give to 'national income' for we shall use 'national income' as a shorthand expression for net product, including major components, and related estimates including social accounts and national plans or budgeting, and distribution of income by size of income. Indeed, it should be understood as encompassing the whole gamut of estimates that is reported on in the Bibliography of this Association.

An 'estimated' figure is distinguished from a 'guessed' figure by a smaller margin of error and this results from basing the estimate on data. How small the margin of error will be depends primarily on the accuracy and completeness with which the underlying data have been compiled and tabulated; the competence and the imagination of the estimator are secondary. The legitimate uses of national income estimates will vary not only with their accuracy but also with the degree of articulated detail with which estimates can be prepared. Clearly the greater the detail, assuming it to be reasonably accurate, the more numerous the uses. Unfortunately, the estimates in under-developed countries, with few exceptions, are not firmly based on reliable census or tax data or on well-designed sample inquiries.

This judgment finds support in the classification of current estimates of 61 countries undertaken at my request by the National Accounts and Financial Statistics Branch, Statistical Office, United Nations. Following Colin Clark, this Office appraised each estimate according to the following scale:

Class I. Based on accurate taxation or production census statistics.

Class II. As above, but with some defects or deficiencies.

Class III. Approximate estimates.

Class IV. Very rough estimates.

${ }^{1}$ It is tempting to add one other attribute as common to all backward areas the absence of the 'capitalistic spirit' which some identify with the 'Protestant ethic'. To pursue this sociologist aspect of the problem would lead us too far astray. 
When the 61 countries are divided into developed and under. developed economies, we find a sharp contrast in the character of estimates. ${ }^{1}$

\begin{tabular}{l|c|c|c|c|c}
\hline & $\begin{array}{c}\text { No. of } \\
\text { Economies }\end{array}$ & $\begin{array}{c}\text { No. Economies } \\
\text { with Specified Class } \\
\text { of Estimate }\end{array}$ \\
\hline $\begin{array}{l}\text { Developed economies } \\
\text { Under-developed economies }\end{array}$ & 24 & 11 & 10 & 3 & - \\
\hline
\end{tabular}

Because of the approximate and rough character of much of the underlying data, estimators with high standards of "statistical ethics' are obliged to forego estimating the detailed components that enter into the global estimates. The remainder of our discussion, however, will consider the uses of national income estimates on the assumption that these severe limitations of existing national income estimates have been eliminated in large part; otherwise there would be little to discuss. For this reason we shall frequently draw for illustrative purposes on the estimates for Puerto Rico, since these estimates are reasonably well founded on census and tax data and have been prepared in considerable detail.

\section{POLICY USES OF INCOME ESTIMATES}

The economic problem of transforming backward areas, in our view, is one of effecting a lasting and continuous rise in the ratio of reproducible capital to population. That is, it is a problem in economic growth, and backward areas constitute only a special case. Now the rôle of national income estimates in studying the process of economic growth, another topic discussed at this Conference, would apply also to the rôle of these estimates in studying the development of the under-developed areas. Such uses obviously would not be unique with the underdeveloped countries. However, I am led to conclude that no matter what economic aspect we consider, the uses of national income estimates will not be solely applicable to the problems of backward nations.

${ }^{1}$ The subjective element in the evaluation of the estimates and in the classification of the economies is readily admitted. 
Professor Simon Kuznets has well stated the general purposes so eminently served by national income and wealth estimates when he notes that one of the motivating considerations in preparing these estimates represents 'the effort by economists and other students of human society to perceive the economy of the nation as a whole; to define the particular aspect that reflects in clear focus its essential functions and structure; to distinguish its major components - groups of economic agents and types of economic activity; and to find a basis upon which both the parts and the whole can be measured to secure comparable magnitudes '. ${ }^{1}$ The uses being general by definition mean they are not unique for any particular type of economy; they are relevant to an equal degree to under-developed as well as industrially advanced economies.

This fact is cited not with the intention of minimizing the uses of national income estimates in under-developed areas. Lack of uniqueness does not impair the contributions of these estimates in delineating economic structure, in summing up the whole economy, in distinguishing significant components and relating them to the whole.

To the extent that under-developed economies are less complex than industrially advanced economies, much will be known of the structural and functional anatomy of the economy by other means of economic observation - census of occupations, roster of exports and imports, etc. Accordingly relatively less knowledge on this score will be contributed by national income estimates. But even in such areas with a relatively simplified economic structure, to gain a summary notion of approximate changes over time in the per capita level of economic well-being, national income and wealth estimates are indispensable. It is probably safe to say that this last use - as barometer of changes in economic well-being - is especially important in those underdeveloped areas where development programs are being implemented. The temporal changes recorded in the income and wealth estimates provide a rough measure of the effectiveness or ineffectiveness of the programs, if the effect of changes outside the progran can be broadly gauged or isolated.

Income estimates relating both the parts and the whole in a

${ }^{1}$ Introduction to the Bibliography on Income and Wealh, Vol. I, 1937-47, International Association for Research in Income and Wealth, p. xi, Bowes \& Bowes, Cambridge, 1952. 
meaningful way make it possible to provide a factual basis for political debates. In Puerto Rico, for example, prior to the development of the income estimates, the belief that absentee owners, chiefly residing in the continental United States, controlled a substantial fraction of the Puerto Rican economy figured prominently in the political and economic thinking of many responsible groups. An approximate measure of the magnitude of absentee ownership can be obtained by relating the net flow of interest, dividends and profits of branch establishments, which in Puerto Rico for the last decade has been an outward flow, to the national income produced on the Island. This calculation for Puerto Rico, based on data that are biassed in the direction of overstating the net outward flow, indicated that the net external flow of property income was less than 5 percent of the net income produced in Puerto Rico during the decade of the 1940's. ${ }^{1}$

Another topic of public discussion was the extent of the contribution by the U.S. Federal Government to the Puerto Rican economy through unilateral grants, subsidies and other activities. National income accounts contributed in two ways to establishing this discussion on a factual basis. First, in the process of constructing the accounts accurate compilations of the large variety of Federal grants and activities in Puerto Rico were derived, and secondly, the relative magnitude of this total could now be indicated by relating it to the appropriate national income total.

Because national income estimates provide 'a basis upon which both the parts and the whole can be measured to secure comparable magnitudes', these estimates were a most valuable aid to the political leaders, and through them to the people of Puerto Rico, in assessing the economic price of any basic change in the Island's political relationship vis-à-vis the United States. For example, the more obvious impacts of complete political independence or statehood upon the Puerto Rican economy are

${ }^{1}$ For the underlying data, see Daniel Creamer, Net Income of the Puerto Rican Economy, 1940-44 (1947), and Jesus Diaz Hernandez, The Net Income of the Puerto Rican Economy Fiscal Years 1939-40 to 1945-46 (Bureau of the Budget, Office of the Governor, San Juan, Puerto Rico, 1949). This compares with 4 percent for Jamaica, 12 percent for Nyasaland and 42 percent for Northern Rhodesia according to estimates of Phyllis Deane, The Measurement of Colonial National Incomes, Occasional Papers XII, National Institute of Economic and Social Research, Cambridge University Press, 1948, Table 105, p. 149. 
known and can be roughly measured. ${ }^{1}$ Once measured and related to the national income total it was clear that the current relationship provides the most favorable economic terms for Puerto Rico.

It may not be amiss to cite two other examples of how national income estimates have assisted responsible political leaders in Puerto Rico to attain a better understanding of some of their problems and the validity of proposed solutions. The annual rate of natural population increase in Puerto Rico during the 1940 's was 1.7 percent, one of the highest rates in the world. The rationalization of a lack of a program for reducing the birth rate, admittedly an extremely difficult problem, was found in the comforting belief that the population problem would solve itself when wage-earner families attain a level of annual income of $\$ 700-800$ in prewar prices. Let us assume that the proposition is a valid one and that the wartime rate of expansion in real per capita income, which was at an uniquely high rate in the recent history of Puerto Rico, continues. How many years must elapse before the stated level of family income is reached? What will be the expected population at that date and what is the real national income implied by the given level of family income and expected population? Rough calculations indicate that it would require 18 years to achieve the required family income, that the Island's population in the meantime would increase by 40 to 50 percent and that the foregoing implied a tripling of the real national income of 1942 . The most sanguine are ready to admit that the resource base (arable land, raw materials and labor force) is such as to make this achievement highly improbable. ${ }^{2}$ To deprive the political and intellectual leaders of their rationalization may be a preliminary to positive action, which is yet to be taken.

The other example illustrates how quantitative limits can be assigned to the economic impact of a given reform. Among the several programs in Puerto Rico designed to improve the economic well-being of the farm laborer, one involves the purchase

${ }^{1}$ An estimate of the loss of income that probably would result from complete independence is attempted in The Net Income of the Puerto Rican Economy, op. cit., pp. 39-41.

2This calculation is carried out in Creamer, op. cit, pp. 23-25. The results presented there must be modified in the light of the more accurate deflation presented in the Gross Product of Puerto Rico, 1940-1944, by Daniel and Henrietta Creamer, University of Puerto Rico, 1948, pp. 71-72, These modifications are taken into account in the text statements above. 
by the Land Authority of sugar lands held by corporations in excess of 500 acres. These plantations, called "proportional profit farms", are operated by Land Authority managers and the profits are divided among the farm workers in proportion to manhours worked by each one. The distribution of the net profits among the workers constitutes a deliberate attempt at a redistribution of income. It is the potentialities of this phase of the program which can be gauged in income terms.

Since the following are known (say) for 1939-40:

(a) Total acreage in sugar cane;

(b) Total acreage subject to expropriation under the legislation;

(c) Net profits earned in the cultivation of sugar cane;

it is a simple matter, on the assumption of equal productivity in the cultivation of public and private lands, to calculate the amount of net profits in 1939-40 that would have been received by the workers on the 'proportional profit farms'. My calculations indicated that about 2 percent of Puerto Rico's national income would have been redistributed in 1939--40 had this program operated at maximum level. The worthwhileness of this program obviously cannot be settled by a simple computation of this sort. It is helpful, however, to be able to assess the quantiative importance of one of the avowed objectives of the program. With national income estimates an approximate measure can be made.

The desire to measure a part of the economy and relate it to the whole assumes unusual force in those under-developed economies where different cultural communities coexist. How is the income distributed between the two communities? What is the relative burden of taxation between such communities and what is the relative distribution of government expenditures? Dr. Ludwig Gruenbaum was able to carry out such estimates for the Arabic and Jewish communities of Palestine under the British Mandatory Government for 1936, thereby providing a factual base to an important political discussion. ${ }^{1}$ And most of us are familiar with Miss Phyllis Deane's estimates of the dis-

'A. Ludwig Gruenbaum, National Income and Outlay th Palestine, 1936, Jerusalem, 1941. 
tribution of national income between different races or sectors (Europeans, Africans, Asiatics and government) in Northern Rhodesia and Nyasaland. ${ }^{1}$

Estimates of income for partial segments other than cultural or racial communities may be significant depending on the circumstances. For example, those interested in the development of the Israeli economy would have a special interest in knowing the fraction of total national income and of specific industries originating in establishments owned and operated by the General Federation of Labor (Histradruth) and how this fraction changes over time. Similar estimates for the firms operated by the Puerto Rican Development Company have had a special interest for Puerto Ricans.

This type of use of national income estimates obviously is not unique with under-developed areas for it does not differ in principle from the practice of preparing regional breakdowns of national or personal income in the developed economies - state estimates of personal income in the U.S.A., for example. Nor can we find unique uses in the possibly legitimate rôle of income estimates in creating and furthering economic developmental processes themselves.

Now, it is a commonplace that the allocations of resources in a national economy are determined either (1) predominantly by the central government (totalitarian economy) or (2) partly by the central government and partly by the decisions of private individuals acting through the market (mixed economy) or (3) predominantly by the market transactions of private individuals (private market or laissez-faire economy). Prior to the Russian revolution of 1917 national economies developed into advanced industrialized nations by following paths (2) or (3). The industrialization of Germany and Japan illustrates development by a mixed economy and the industrialization of Great Britain and the United States by a predominantly laissez-faire economy. In the future it is unlikely that under-developed areas will develop by following the principles of laissez-faire where state direction is at a minimum. Rather they will develop as mixed or fully regimented economies. Expressed in the more illuminating terminology of Professor Jewkes they will be characterized either as " "assisted" transitions to industrialization in the sense that state intervention (is) limited either in extent or time and where,

${ }^{1}$ Deane, op. cit., Table 106, p. 150. 
normally, investment (is) provided, at least in part, from outside" or as " "engineered" transitions where the state provides most of the driving force and deliberately organizes the sacrifices necessary for investment'. ${ }^{1}$ Even if non-economic considerations should not intervene, state intervention is bound to be above the minimum to overcome the disadvantages of a late start. This factor was partly responsible for the 'assisted' transition of Germany and Japan in the latter half of the nineteenth century and it must operate with greater force a century later.

State intervention above the laissez-faire level will emerge for still another reason - to create the economic and cultural prerequisites for development, no part of which will prove attractive to private investors, certainly at the outset. Thus public health programs to rid populations of enervating diseases, educational programs to make populations literate - a preliminary to vocational, technical and professional training-systems of transportation and communication and development of power, all are bound to become the responsibility of the state and in this manner call into being an assisted transition or mixed economy.

When non-economic objectives are paramount, the industrialization process is more likely to be 'engineered', or totalitarian, in character. That is, industrialization in such cases is not primarily directed to raising the level of economic wellbeing but it is regarded as a means of achieving political goals - such as the absorption of a larger population by Israel for reasons of nationalism and self-defense or the fulfillment of communist dogma as in China. Virtually all efforts in such cases must be controlled and directed toward the attainment of these objectives.

In the case of an engineered transition by the state the rôle of national income estimates in the form of social accounts seems clear. If complete chaos is to be avoided, planning in the form of detailed social accounts is indispensable and the targets established in these accounts assume an imperative character for the various administrative agencies of the state. ${ }^{2}$ Accordingly, it is no accident that the Israeli Government has issued a

I John Jewkes, The Growth of World Industry, Oxford Economic Papers (New Series), Vol. 3, February 1951, No. 3, p. 6.

${ }^{2}$ Gerhard Colm, Experiences in the Use of Social Accounting in Public Policy in the United States, Income and Wealth Series I, published for the International Association for Research in Income and Wealth by Bowes \& Bowes, Cambridge, England, 1951, pp. 75-98. 
detailed four-year development plan prepared by Dr. Gaathon. ${ }^{1}$ Whether the imperatives can be heeded depends on how intelligently they have been formulated and how well the economy is insulated against factors that originate outside of its own borders. However, it must be emphasized once more that this use of national income estimates is common to all 'engineered' economies whether they be developed or under-developed.

In the case of an 'assisted' transition the formulation of a set of social accounts can serve as orientation, as Colm says, for governmental authorities, especially with respect to fiscal policy. ${ }^{2}$ And fiscal policy could have an important tôle to play during the transitional period because of the inflationary pressures that will be created by the relatively large investments based primarily on foreign loans or grants. Again, however, it is necessary to point out that such use of income estimates is not unique with under-developed economies.

If the basic characteristic of under-developed areas is the small amount of capital per worker, the problem in its simplest terms, as previously noted, is one of increasing the amount of capital per worker to a sufficiently high level and on a sustaining basis. In other words, the problem that transcends all others in importance is how to discover the specific opportunities for profitable investment. The type of economic analysis that holds out any hope of providing some of these answers obtains little help from national income and related estimates. The categories of the latter are simply not relevant to the analysis of the economics of location of industry.

Of the various analyses of the industrialization of backward areas that have come to my attention the one by Professor W. Arthur Lewis for the British West Indies, in my judgment, provides the keenest insights. ${ }^{3}$ Yet the analysis has not a single reference to the national income estimates of the area and I believe this omission in no way reduces the effectiveness of his analysis. Not only do national income estimates have little to

'A. Ludwig Gaathon, 'Four Year Development Plan of Israel, 1950-1953', Prime Minister's Office, Department of Economic Research, Hakirya, March 1950 (mimeographed).

${ }^{2}$ Several of the papers presented to the Cambridge meeting of this Association on social accounting conclude that among the primary functions of social accounting is the guidance it provides on fiscal policy. See particularly the papers by Erik Lundberg and E. F. Jackson. The latter is published in Income and Wealth Series I, op. cit., pp. 148-59.

3 The Industrialization of the British West Indies, Caribean Economic Review, Vol. II, No. 1, May 1950 , p. 61. 
contribute to this crucial area of research, but income estimates in the form of projected social accounts (national plans or budgets) cannot have any claim to being valid targets unless this fundamental research has been done. ${ }^{1}$

If these judgments are correct, is there not some danger that specialists in national income estimates may have been too zealous in promoting their specialty with the governmental authorities in under-developed areas? Since all these areas are characterized by scarcity of professional personnel at the service of government, perhaps relatively more resources should have been devoted to fundamental economic analysis and less to national income estimates. On occasion one senses the existence of the naive belief that economic salvation can be achieved by the creation of statistical measures. Some are prone therefore to pay too high price for acquiring the measurements. In Puerto Rico, for example, a systematic analysis of investment opportunities on a continuing basis is only now being considered. Yet the authorities have seen fit to have prepared an input-output table according to the Leontieff model which has validity only if the industry 'mix' and productivity remain constant. This is a most unrealistic assumption, for an under-developed area can develop only by changing its industry ' $\mathrm{mix}$ ' and productivity. This particular statistical gadget then probably will have little use. As specialists we can serve under-developed economies also by exercising restraint in promoting our special measurements.

\section{CONCLUSIONS}

To the question 'What are the uses of National income estimates in under-developed countries?' our answer, which perhaps is obvious, is that the uses of national income estimates are general, applicable alike to developed and under-developed economies. Specific uses will depend on the degree of accurate detail with which the estimates can be prepared and the econo-

1 This condition does not seem to have been fulfilled in setting the economic targets in 1960 for Puerto Rico as set forth in 'Economic Development, Puerto Rico, 1940-1950 and 1951-1960', issued by the Economics Division of the Puerto Rican Planning Board (January 1951, mimeographed). One might characterize this type of mechanical extrapolation as the modern version of political arithmetic. By fundamental research $\mathrm{I}$ have in mind economic analysis directed toward the deternination of specific possibilities for profitable investment and how these possibilities can be developed. 
mic circumstances and proposals that are of special interest or significance to a given area. When the available information is sufficient only to approximate the national income total, which characterizes all too often the estimates in under-developed areas, the estimate has only one use - to gauge the changes in economic well-being over time. When the articulation of the economy can be described by estimates of significant components, the uses are extended through the possibility of relating the parts of the economy to a total in a meaningful manner. However, no matter what degree of articulation can be achieved in the national income estimates they cannot substitute for fundamental economic analysis to determine the opportunities for profitable investment, whether by the state or private enterprise. This is absolutely essential if an under-developed area is to be transformed. At best national income estimates can provide some data for the analytical task. 